\title{
Sleeve lobectomy as an alternative to pneumonectomy in patients with operable lung cancer
}

\author{
M. KASPRZYK*, W. DYSZKIEWICZ, C. PIWKOWSKI, M. BRUDLO, B. GALECKI, P. GABRYEL, L. GASIOROWSKI \\ Department of Thoracic Surgery, Poznan University of Medical Sciences, 62 Szamarzewski St., 60-569 Poznan, Poland \\ *Correspondence: kasprzykmariusz@hotmail.com
}

Received April 5, 2012 / Accepted July 5, 2012

\begin{abstract}
In many patients with non-small cell lung cancer (NSCLC), pneumonectomy is still the only choice of surgical treatment. Pneumonectomy is associated with the increased risk of postoperative complications and higher mortality. Late results are affected by progressive deterioration of the quality of life. In some patients, especially with central location of the tumor the sleeve lobectomy can be an alternative to pneumonectomy. However, there are some doubts about the higher risk of local recurrence. The aim of the study was to assess the early and late results of sleeve lobectomy in patients with NSCLC treated surgically.

The study group consisted of 107 patients subjected to surgery due to NSCLC between 2001 and 2009. There were 89 male and 18 female patients, aged between 35 and 78 years (mean age: 65 years). Surgery was preceded by routine diagnostic and staging procedures. Statistical analysis was based on the Statistica 6.0 software.

The following sleeve lobectomies were performed: 71 right upper, 29 left upper, 5 left lower lobectomies, one inferior bilobectomy and one upper bilobectomy. Twelve patients were subjected to left upper sleeve lobectomy with partial resection and reconstruction of the pulmonary artery. Squamous cell carcinoma (SCC) was the most common type of histology. Most patients were classified as stage IB and IIB. Perioperative mortality in the entire study population was $1.8 \%$. The most frequent complications were as follows: supraventricular arrhythmias (11.2\%) and atelectasis of the operated lung (10.3\%). The fiveyear survival after surgery was $56.1 \%$. Local recurrence was observed in 10 patients $(9.3 \%)$. Statistical analysis demonstrated that $\mathrm{T}$ stage and postoperative chemotherapy were significant factors influencing long-term survival. Multivariate analysis showed that $\mathrm{T}$ stage was the only factor influencing the long-term survival.

Sleeve lobectomy is a good alternative to pneumonectomy in selected patients with NSCLC. Although it is considered as technically difficult, it is characterized by lower risk of death during the perioperative period, lower percentage of significant postoperative complications and better quality of life after the operation.
\end{abstract}

Key words: lung cancer, surgical treatment, sleeve resection

Despite the progress in oncological therapies which was achieved in the recent years, surgery remains the most effective method of treatment for lung cancer. The extent of the resection correlates with the frequency of local recurrence and survival after treatment. In case of pneumonectomy, late results are affected by a progressive deterioration of quality of life and this important factor should be carefully considered before the operation. Pneumonectomy, which for years was the only method of surgical treatment in patients with central tumor location, carries the risk of a significantly higher postoperative mortality and morbidity. Furthermore, long-term follow-up after pneumonectomy shows the development of pulmonary hypertension and respiratory insufficiency, factors which adversely affect the quality and duration of life after the operation. Since the eighties of the past century lung parenchymal- sparing operations have been introduced, such as sleeve lobectomy with or without pulmonary artery reconstruction. Many thoracic surgery centers consider the above-mentioned procedures as standard treatment, if technically feasible, regardless whether the patient is qualified for pneumonectomy. For years discussion is under way considering the influence of sleeve lobectomy on local cancer recurrence, as compared to pneumonectomy.

The aim of the study was to evaluate the early and late results of surgical treatment in patients with NSCLC who underwent a sleeve lobectomy in a single thoracic surgery center . 


\section{Patients and methods}

Between 2001 and 2009, 107 sleeve lobectomies (lobectomy and bilobectomy) were carried out at the Department of Thoracic Surgery, University of Medical Sciences in Poznan, Poland in patients diagnosed with NSCLC. The study group consisted of 89 male and 18 female patients aged between 35 and 78 years (mean age: 65 years). Preoperative diagnostics or intraoperative histological evaluation revealed the presence of NSCLC in each case.

Preoperatively the following examinations were performed on a routine basis: standard blood tests, EKG, spirometry, chest $\mathrm{x}$-ray and computer tomography, abdominal ultrasound and flexible bronchoscopy. Additionally, in selected cases the following examinations were done: echocardiography, positron emission tomography (PET-CT), transthoracic tumor biopsy, abdominal or head computer tomography and bone scan. In patients with enlarged mediastinal lymph nodes mediastinoscopy was performed, prior to the potential resection of the pulmonary tumor. Patients without mediastinal lymph node metastases were qualified for surgical treatment, patients with a positive $\mathrm{N} 2$ feature for neoadjuvant chemotherapy, while those with N3 lymph node metastases were excluded from surgery.

The surgical procedure was performed under general anesthesia with bronchial intubation by means of the antero-lateral or postero-lateral thoracotomy approach. After preparation, ligation, and dissection of appropriate branches of pulmonary vein and artery supplying the pulmonary lobe, the patient was assessed whether a sleeve lobectomy may be performed. A frozen section of the proximal and distal bronchial stump was performed, in order to exclude neoplastic infiltration of the surgical incision line. Bronchial end-to-end anastomosis was performed using interrupted or continuous monofilament PDS or Maxon 4-0 sutures. In case of a significant disproportion between the diameters of the lumen of the anastomosed bronchi, continuous sutures were used to tightly close the lumen of the main bronchus. After exclusion of an air leakage from the anastomosis line, it was subsequently covered by a pedunculated, intercostal muscular, parietal pleura or pericardial patch, in order to reduce the risk of broncho-pleural or broncho-arterial fistula development. Each patient underwent a complete mediastinal lymphadenectomy. The surgical procedure was terminated after the introduction of two drains into the pleural cavity (28-32 F in diameter), which were usually removed on the third day after the operation, provided a complete lung expansion on the chest $\mathrm{x}$-ray, absence of air leakage, and daily drainage less than $150 \mathrm{ml}$. After surgery we performed fiberoptic bronchoscopy in each patient to aspirate bloody content and secretion from the bronchial tree, as well as to evaluate the anastomotic site. In the absence of other indications (lung atelectasis on chest $\mathrm{x}$-ray, leakage or stenosis of the bronchial anastomosis) re-bronchoscopy was performed on the seventh postoperative day, prior to patient discharge from the hospital and three months after surgery. Each patient was referred to a medical oncologist, and depending on the stage of the tumor (UICC
TNM classification from 1987 revised in 1997 and 2009), general patient condition and comorbidities, qualified for adjuvant therapy (chemo- or radiotherapy). The patients with IIB stage or more advanced disease were candidates for systemic therapy. Follow up of patients were provided by outpatient oncology and thoracic surgery clinics, and consisted of the following: history and physical examination, chest $\mathrm{x}$-ray, abdominal ultrasound, and in case abnormal examination results, additional diagnostic regimen such as computer tomography or MRI of the head, bone scintigraphy, or PET-CT was initiated.

The follow-up of patients after surgery was based on questionnaires sent to them, documentation from the oncology and surgery outpatient clinics, as well as information obtained from family doctors.

Statistical analysis was performed on the basis of the Statistica 6.0 (Statsoft Inc., USA) program. The Gehan, t-Student and $\mathrm{Chi}^{2}$ tests with Yates correction were used. The survival function was estimated by means of the Kaplan-Meier's method.

\section{Results}

Among 107 operated patients in 71 right upper sleeve lobectomy, in 29 left upper sleeve lobectomy, in 5 left lower sleeve lobectomy, in 1 upper bilobectomy and in 1 lower bilobectomy were carried out. Twelve patients were subjected to upper left sleeve lobectomy with pulmonary artery reconstruction or segmental resection with end-to-end anastomosis. SCC predominated among the NSCLC subtypes (72\%). Forty-one $(38.3 \%)$ patients who underwent surgery were staged as IB, 40 (37.4\%) as IIB, and 22 (20.6\%) as IIIA. Mediastinoscopy before planned resection was performed in 18 patients- in 4 patients

Table 1. Clinical data

\begin{tabular}{lc}
\hline Histological type & $77(72 \%)$ \\
Squamous cell cancer & $22(20.6 \%)$ \\
Adenocarcinoma & $3(2.8 \%)$ \\
Large cell carcinoma & $2(1.8 \%)$ \\
Typical carcinoid & $2(1.8 \%)$ \\
Glandular-squamous mixed carcinoma & $1(0.9 \%)$ \\
Carcinosarcoma & \\
TNM classification & $1(0.9 \%)$ \\
IA & $41(38.3 \%)$ \\
IB & $40(37.4 \%)$ \\
IIB & $22(20.6 \%)$ \\
IIIA & $2(1.8 \%)$ \\
IIIB & $1(0.9 \%)$ \\
IV & \\
Cancer differentiation & $9(8.4 \%)$ \\
G1 & $73(68.2 \%)$ \\
G2 & $25(23.4 \%)$ \\
G3 & \\
Feature R & $102(95.3 \%)$ \\
R0 & $5(4.7 \%)$ \\
R1 &
\end{tabular}




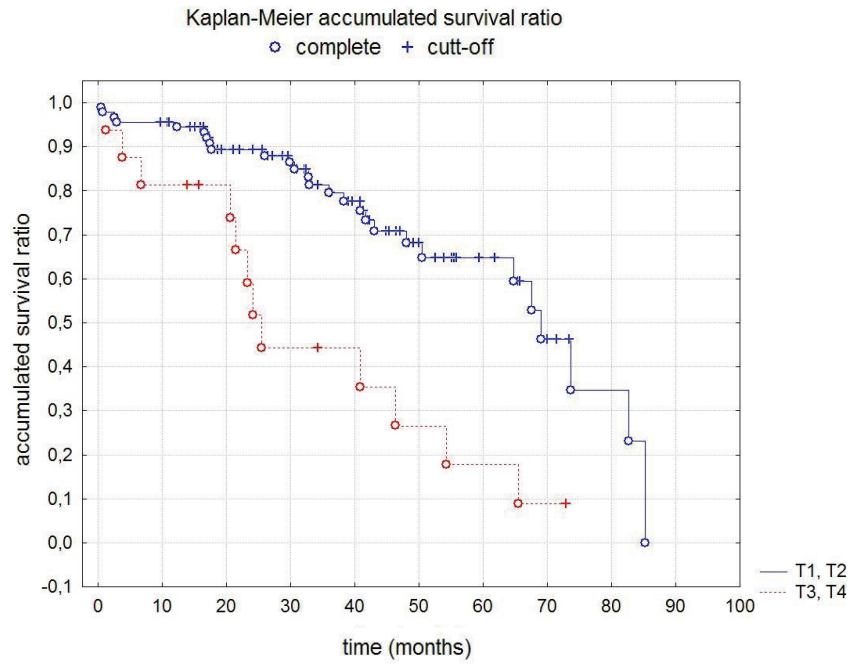

Figure 1. Five-year survival according to $\mathrm{T}$ stage

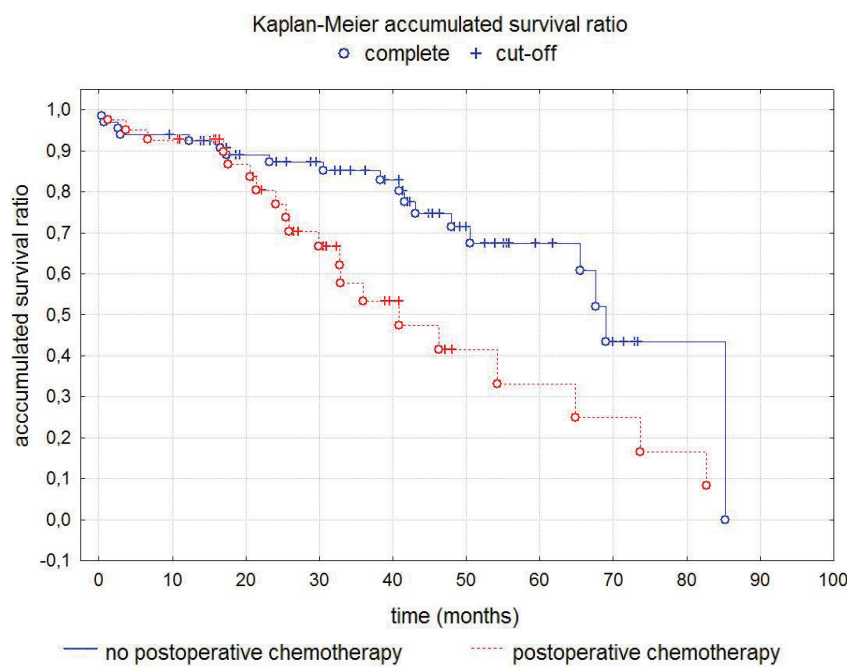

Figure 2. Long-term survival according to postoperative chemotherapy

Table 2. Postoperative complications

\begin{tabular}{lc}
\hline Postoperative bleeding requiring re-thoracotomy & $2(1.8 \%)$ \\
Prolonged air leakage more than 7 days & $8(7.5 \%)$ \\
Lung atelectasis requiring bronchoaspiration & $11(10.3 \%)$ \\
Pneumonia & $1(0.9 \%)$ \\
Broncho- pleural fistula & $6(5.6 \%)$ \\
Residual pneumothorax & $6(5.6 \%)$ \\
Wound infection & $1(0.9 \%)$ \\
Supraventricular arrhythmias & $12(11.2 \%)$ \\
Stenosis of the bronchial anastomosis & $3(2.7 \%)$ \\
Left recurrent laryngeal nerve paralysis & $3(2.7 \%)$ \\
Postoperative psychosis & $3(2.7 \%)$ \\
\hline
\end{tabular}

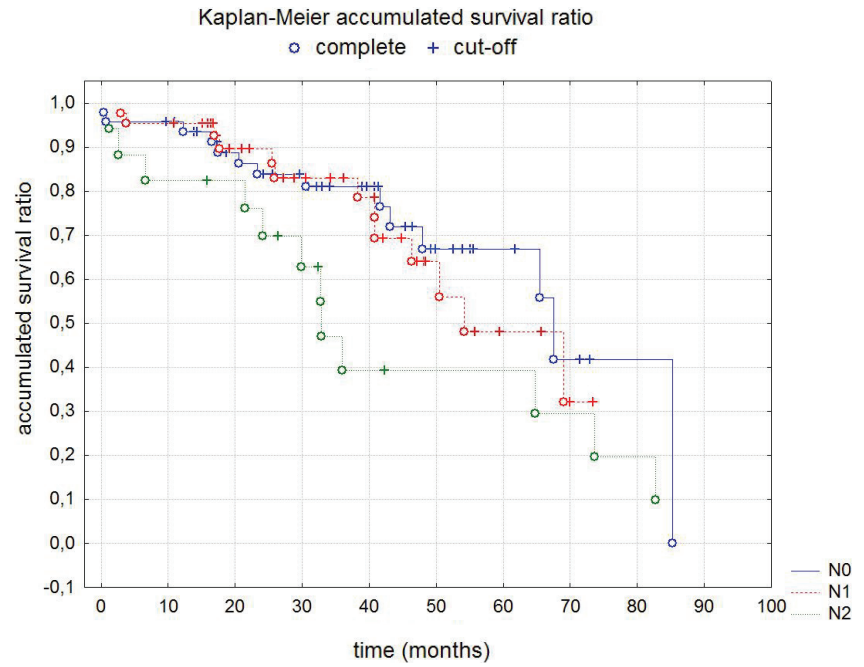

Figure 3. Five-year survival according to $\mathrm{N}$ stage

N2 disease was found. Fourteen patients were diagnosed with feature T3 (8 patients underwent visceral pleura resection, three- resection of 1-2 ribs, while in 3 patients feature T3 resulted from the infiltration of the main bronchus less than $2 \mathrm{~cm}$ from the tracheal bifurcation). Tab.1 shows the clinical data concerning the histopathological type of cancer, stage of disease, and carcinoma cell differentiation. Four patients underwent preoperative chemotherapy with good response to treatment. In 102 (95.3\%) patients the proximal and distal bronchial incisional line was free from tumor infiltration (R0). Five $(4.7 \%)$ patients were diagnosed with infiltration of the incision line (feature R1). 31 (29\%) patients were subjected to postoperative chemotherapy, 12 (11.2\%) to postoperative radiotherapy, and $10(9.3 \%)$ to postoperative chemoradiotherapy.

Hospital mortality was $1.8 \%$ (2 patients). One patient died due to massive hemorrhage from the pulmonary artery as the result of broncho-pleural fistula, while the second patient died because of pneumonia and sepsis. Minor postoperative complications developed in 33 patients (30.8\%). The most common were as follows: supraventricular arrhythmias (12 patients-11.2\%), atelectasis of the operated lung (11 patients-10.3\%), and prolonged air leakage (8 patients-7.5\%). In $6(5.6 \%)$ patients broncho-pleural fistula was developed: two of them were treated by means of pleural drainage and the use of antibiotics and another three underwent rethoracotomy. One patient required completion pneumonectomy and in two patients fistula closure and pleural cavity drainage were carried out with good results. Significant stenosis at the site of the bronchial anastomosis was observed in $3(2.7 \%)$ patients. These patients were treated with the use of bronchoscopic dilatation and/or stenting. Tab.2 shows the rate of selected postoperative complications.

Five years after surgery, 60 (56.1\%) patients survived, 38 (35.5\%) were confirmed as deceased, and nine $(8.4 \%)$ were 
lost to follow-up. In $68.4 \%$ of cases distant metastases were the cause of death, in $26.3 \%$ - local recurrence, and in 5.3\% death was not related to lung cancer. In the study group the local recurrence was diagnosed in $10(9.3 \%)$ patients. However, none of them survived five years. In statistical analysis two factors significantly influenced survival: feature $T(p=0.00072$; Fig. 1$)$ and postoperative chemotherapy $(\mathrm{p}=0.036)$. Postoperative chemotherapy had an adverse effect on long-term survival (Fig.2). When analyzing the influence of node status on survival, patients were divided into two groups: patients with N0 or N1 features, and those with N2 lymph node metastases. The five-year survival probability was significantly lower in patients with N2 stage ( $\mathrm{p}=0.02)$. Determining the Kaplan-Meier curves for each group separately (N0, N1, N2) we observed differences in survival, however, statistically non significant ( $p=0.06$; Fig. 3). Patient age, gender, histological type, stage of cancer, resection of the pulmonary artery, preoperative chemotherapy, and postoperative radiotherapy had no influence on survival. However, in a multivariate statistical analysis, only T stage significantly influenced long-term results $(\mathrm{p}=0.0013)$. The remaining parameters did not correlate significantly with survival ( $\mathrm{N}: \mathrm{p}=0.18$; postoperative chemotherapy: $\mathrm{p}=0.31$ ).

\section{Discussion}

In 1947, Clement Price Thomas was the first to perform sleeve lobectomy in a patient with right bronchial adenoma. In case of lung cancer, Allison was the first to use the technique in 1952, in addition to pulmonary artery reconstruction. In 1970, Paulson et al. and in 1972, Jensik et al. presented their study results considering a group of 50 patients subjected to surgical intervention, due to lung cancer. In 1971, Pichlmeier and Spelsberg described the technique of double sleeve lobectomy. In Poland, Olechnowicz et al. were the first to perform sleeve lobectomy with pulmonary artery reconstruction (1). Sleeve lobectomy was described as an alternative to pneumonectomy in patients with limited respiratory reserve, in whom pneumonectomy would be associated with increased risk of respiratory failure. This mainly applies to patients with cancer located in the origin of the bronchus and coexisting COPD. Originally, many concerns about this type of therapy were formulated. They mainly concerned the high risk of local recurrence at the site of the bronchial anastomosis and complications associated with the bronchial anastomosis (fistula, or anastomotic stenosis). As time passed and with the experience gained by the thoracic surgeons in performing sleeve lobectomy, these procedures were used more frequently in patients without contraindications to pneumonectomy. Currently, sleeve lobectomies are typically performed in patients with lung cancer in most thoracic surgery centers, provided that there are technical possibilities to cut and anastomose the bronchial stumps within healthy tissue margins.

Perioperative mortality in case of sleeve lobectomy is similar to that observed in case of standard lobectomies, ranging between $1.2 \%$ and $5.3 \%(2-7)$. It is significantly lower than the mortality rate observed in case of patients after pneumonectomy, which can be as high as $11.2 \%(5,7-11)$, especially in patients in whom right-sided pneumonectomy was preceded by induction chemotherapy (12). Bagan et al. compared the perioperative mortality between upper right-sided lobectomy (756 patients), upper right-sided sleeve lobectomy (66 patients), and right-sided pneumonectomy (151 patients). The mortality rate was $2.9 \%, 4.5 \%$ and $12.6 \%$, respectively (10). Our inhospital mortality was $1.8 \%$, which is similar to the data in the literature. Of the two deceased, one died due to massive bleeding from the pulmonary artery during the course of broncho-pleural fistula accompanied by pleural empyema. The second patient died because of massive pneumonia and sepsis. The presence of a broncho-arterial fistula after sleeve lobectomy is a rare, but usually a fatal complication. The fistula rate ranged between $1.8 \%-2.6 \%$, with the mortality as high as $70 \%$ (13-15). The primary method to prevent the occurrence of this complication is to avoid the destruction of the bronchial arteries and cover the bronchial anastomotic line by means of a pedunculated muscular flap or other tissue (visceral pleura, pericardium), in order to reduce the risk of anastomotic leakage and separate it from the pulmonary artery wall. In the presented case the bronchus was covered by a visceral pleural flap. Based on our experience and reports of other authors, one can conclude that the best material used to cover the bronchial anastomosis is the pedunculated intercostal muscle.

One of the most serious complications after anatomical lung resections is the development of broncho-pleural fistula. A particularly high percentage of fistulas is observed in patients after pneumonectomy, according to different authors ranging between $3.6 \%$ and $16 \%(5,8,10)$. This is one of the leading causes of mortality following pneumonectomy (16). The occurrence of fistulas at the site of the anastomosis after sleeve lobectomies is slightly higher, as compared to classical lobectomies (1.2-7.5\%). However, considerably lower than in case of pneumonectomy $(3,13,17)$. One of the main causes of fistula development is the devitalization of the bronchus associated with extensive lymphadenectomy. Other reasons include the following: bronchial stump inflammatory lesions, diabetes mellitus, postoperative chemo- and radiotherapy, chronic steroid therapy, cachexy, low protein and albumin levels, and technical errors during bronchial stump anastomosis. In our study group bronchial fistulas were observed in six (5.6\%) patients. It seems that the relatively small percentage of fistulas was associated with the operative technique, sparing the small vessels supplying the bronchi, and coverage of the suture line by a pedunculated intercostal muscle flap.

Stenosis of the bronchial anastomosis is considered as a late complication following sleeve lobectomy. The occurrence rate of the stenosis ranges between $1.7 \%$ and $20 \%$, according to the literature $(13,14,18)$. The complication was probably due to technical errors, which occurred during the anastomosis of bronchial stumps, high tension on the suture line, and bronchial microfistulas. Stenosis may be either a hard, fibrous scar tissue or inflammatory granulation tissue. The 
treatment of anastomotic stenosis consists of expanding the constricted area by means of a rigid bronchoscope with laser removal of the granulation tissue, or temporary stent implantation in place of the anastomosis. If there is no improvement after conservative treatment in patients with severe stenosis, pneumonectomy should be considered. In our study group, a clinically significant stenosis was observed in three patients. In all cases conservative therapy was sufficient (bronchoscopic dilatation and laser therapy or in one patient- temporary tracheal-bronchial Y stent implantation).

Five-year survival in patients with NSCLC who underwent surgical treatment depends mainly on the involvement of local lymph nodes. The presence of N2 lymph node metastases worsened prognosis. The five-year survival in such patients ranged between $10-15 \%(11,12,14,19,20)$. Most patients died within two years after the operation, due to neoplastic disease recurrence. In $80 \%$ of these cases death is related to distant metastases and only in $20 \%$ to local recurrence of the disease. Comparison of the five-year survival, considering patients after pneumonectomy and sleeve lobectomy demonstrated better results in the latter group $(4,10,17,19)$. Currently most authors agree that patients after sleeve lobectomies are at similar risk of local recurrence as patients subjected to classic lobectomies or pneumonectomies $(2-4,12,15,20)$. The five-year survival rate in the investigated group was $56.1 \%$, and the only factor significantly influencing survival was the $\mathrm{T}$ feature. A local recurrence was observed in $9.3 \%$ of patients (10 patients including 3 with feature R1). In most cases mortality was related to cancer relapse, predominantly due to distant metastases $(68.4 \%$,$) . In our opinion, the greatest advantage of sleeve$ lobectomy is the fact that, with relatively low mortality and morbidity rates, the quality of life and respiratory function is much better than after pneumonectomy (21-24).

\section{Conclusions}

Sleeve lobectomy is a good alternative to pneumonectomy in selected patients with NSCLC. Although a sleeve resection is considered as technically difficult, it is characterized by lower risk of death during the perioperative period, lower percentage of significant postoperative complications (especially bronchial fistulas) and better quality of life after the operation. Late results are also in favor of sleeve lobectomy. The local recurrence rate is similar to that one after standard lobectomy, and the five-year survival rate is better as compared to pneumonectomy.

\section{References}

[1] OLECHNOWICZ H., BOGDAN J., SAWICKA E., KOLB P., MIRSKI A.: Sleeve upper lobectomy with resection of the pulmonary artery in surgical treatment of lung cancer. Pneumonol Pol 1984; 52; 187-193.

[2] YILDIZELI B., FADEL E., MUSSET S., FABRE D., CHATAIGNER O. et al.: Morbidity, mortality and long-term survival after sleeve lobectomy for non-small cell lung cancer. Eur J Cardiothorac Surg 2007; 31; 95-102. http://dx.doi. org/10.1016/j.ejcts.2006.10.031

[3] FERGUSON M., KARRISON T.: Does pneumonectomy for lung cancer adversely influence long-term survival? J Thorac Cardiovasc Surg 2000; 119; 440-448. http://dx.doi. org/10.1016/S0022-5223(00)70121-8

[4] DESLAURIERS J., GREGOIRE J., JACQUES L., PIRAUX M., GUOJIN L. et al.: Sleeve lobectomy versus pneumonectomy for lung cancer : a comparative analysis of survival and sites of recurrences. Ann Thorac Surg 2004; 77; 1152-1156. http:// dx.doi.org/10.1016/j.athoracsur.2003.07.040

[5] LUDWIG C., STOELBEN E., OLSCHEWSKI M., MASSE J.: Comparison of morbidity, 30-day mortality and long-term survival after pneumonectomy and sleeve lobectomy for non-small cell lung carcinoma. Ann Thorac Surg 2005; 79; 968-973. http://dx.doi.org/10.1016/j.athoracsur.2004.08.062

[6] VOGT-MOYKOPF I., TOOMES H., HEINRICH S.: Sleeve resection of the bronchus and pulmonary artery for pulmonary lesions. J Thorac Cardiovasc Surg 1983; 31; 193-198. http://dx.doi.org/10.1055/s-2007-1021979

[7] MA Z., DONG A., FAN J., CHENG H.: Does sleeve lobectomy concomitant with or without pulmonary artery reconstruction (double sleeve) have favorable results for non-small cell lung cancer compared with pneumonectomy? A meta-analysis. Eur J Cardiothorac Surg 2007; 32; 20-28. http://dx.doi. org/10.1016/j.ejcts.2007.03.018

[8] STOELBEN E., SAUERBREI W., LUDWIG C., HASSE J.: Tumor stage and early mortality for surgical resections in lung cancer. Arch Surg 2003; 388; 116-121.

[9] KIM JOON D., LEE GU J., LEE YOUNG CH., PARK I., CHUNG YOUNG K.: Long-term survival following pneumonectomy for non-small cell lung cancer: clinical implications for follow-up care. Chest 2007; 132; 178-184. http://dx.doi.org/10.1378/chest.07-0554

[10] BAGAN P., BERNA P., PEREIRA NEVES J., BARTHES F., FOUCAULT Ch. et al: Sleeve lobectomy versus pneumonectomy: tumor characteristics and comparative analysis of feasibility and results. Ann Thorac Surg 2005; 80; 2046-2050. http://dx.doi.org/10.1016/j.athoracsur.2005.06.045

[11] MLEKODAJ S., STADNICKI M., SEWERYNIAK W., SZMIGRODZKI L., BOGDAN J. et al.: Five-year follow-up in patients surgically treated because of non-small cell lung cancer. Pneumonol Alergol Pol 1993; 61; 509-517.

[12] VAN SCHIL P., DE LA RIVIERE A., KNAEPEN P.: Longterm survival after bronchial sleeve resection: univariate and multivariate analysis. Ann Thorac Surg 1996; 61; 1087-1091. http://dx.doi.org/10.1016/0003-4975(96)00006-9

[13] KAWAHARA K., AKAMINE S., TAKAHASHI T., NAKAMURA A., MURAOKA M. et al.: Management of anastomotic complications after sleeve lobectomy for lung cancer. Ann Thorac Surg 1994; 57; 1529-1532. http://dx.doi.org/10.1016/ 0003-4975(94)90115-5

[14] TEDDER M., ANSTADT M., TEDDER S., LOWE J.: Current morbidity, mortality and survival after bronchoplastic procedures for malignancy. Ann Thorac Surg 1992; 54; 387-391. http://dx.doi.org/10.1016/0003-4975(92)91413-4 
[15] TERZI A., LONARDONI A., FALEZZA G.: Sleeve lobectomy for non-small cell lung cancer patients and carcinoids: results in 160 cases. Eur J Cardiothorac Surg 2002; 21; 888-893. http://dx.doi.org/10.1016/S1010-7940(02)00085-4

[16] SEPIOLO M., SKOKOWSKI J.: Postoperative pulmonary complications In patients with lung cancer. Pol Przeg Chir 1999; 71; 885-892.

[17] TAKEDA S., MAEDA H., KOMA M., MATSUBARA Y., SAWABATA N. et al.: Comparison of surgical results after pneumonectomy and sleeve lobectomy for non-small cell lung cancer: trends over time and 20-year institutional experience. Eur J Cardiothorac Surg 2006; 29; 276-280. http://dx.doi. org/10.1016/j.ejcts.2005.12.017

[18] UNGAR J., GYENEY J., SCHERER E., SZARVAS J.: Sleeve lobectomy- an alternative to pneumonectomy in the treatment of bronchial carcinoma. J Thorac Cardiovasc Surg 1981; 29; 41-46. http://dx.doi.org/10.1055/s-2007-1023439

[19] OKADA M., YAMAGISHI H., SATAKE S., MATSUOKA H., MIYAMOTO Y. et al.: Survival related to lymph node involvement in lung cancer after sleeve lobectomy compared with pneumonectomy. J Thorac Cardiovasc Surg 2000; 119; 814-819. http://dx.doi.org/10.1016/S0022-5223(00)70018-3
[20] HOLLAUS P., WURNIG P., PRIDUN N.: The natural history of recurrence after bronchoplastic procedures for non-small cell lung cancer. Ann Thorac Surg 2003; 76; 363-369. http://dx.doi. org/10.1016/S0003-4975(03)00337-0

[21] GOMEZ-CARO A., GARCIA S., REGUART N., CLADELLAS E., ARQUIS P. et al.: Determining the appropriate sleeve lobectomy versus pneumonectomy ratio in central non-small cell lung cancer patients: an audit of an aggressive policy of pneumonectomy avoidance. Eur J Cardiothorac Surg 2011; 39; 352-359. http://dx.doi.org/10.1016/j.ejcts.2010.07.002

[22] PARK J.S., YANG H.C., KIM H.K., KIM K., SHIM Y.M. et al.: Sleeve lobectomy as an alternative procedure to pneumonectomy for non-small cell lung cancer. J Thorac Oncol 2010; 5; 517-520. http://dx.doi.org/10.1097/JTO.0b013e3181d0a44b

[23] DESLAURIERS J., TRONC F., GREGOIRE J.: History and current status of bronchoplastic surgery for lung cancer. Gen Thorac Cardiovasc Surg 2009; 57; 3-9. http://dx.doi. org/10.1007/s11748-008-0316-X

[24] KHARGI K., DUURKENS V.A.M., VERZIJLBERGEN F.F., HUYSMANS H.A., KNAEPEN P.J.: Pulmonary function after sleeve lobectomy. Ann Thorac Surg 1994; 57; 1302-1304. http://dx.doi.org/10.1016/0003-4975(94)91380-3 